\title{
Infection Status with Clonorchis sinensis Metacercariae in Fish from Yangcheon (Stream) in Sancheong-gun, Gyeongsangnam-do, Korea
}

\author{
Woon-Mok Sohn ${ }^{1, *}$, Byoung-Kuk Na1, Shin-Hyeong $\mathrm{Cho}^{2}$, Jung-Won $\mathrm{Ju}^{2}$ \\ 'Department of Parasitology and Tropical Medicine, and Institute of Health Sciences, Gyeongsang National University College of Medicine, \\ Jinju 52727, Korea; '2Division of Vectors and Parasitic Diseases, Centers for Disease Control and Prevention, Osong 28159, Korea
}

\begin{abstract}
The infection status with Clonorchis sinensis metacercariae (CsMc) was examined in freshwater fishes from Yangcheon (a branch of Gyeongho-gang), which is located in Sancheong-gun, Gyeongsangnam-do, the Republic of Korea. Total 2,201 fishes in 26 species were examined by the artificial digestion method through 7 years. CsMc were detected in 1,171 (53.2\%) fishes in 21 spp. (80.8\%) and their density was 85 per fish infected. Total 532 (99.6\%) out of 534 Pungtungia herzi (index fish) examined were infected with $147 \mathrm{CsMc}$ per fish infected. Metacercarial densities in this fish were highest in 2015 (179 CsMc), followed by 2012 (168), 2013 (152), 2016 (145), 2014 (114), and 2017 (89) respectively. In the gobioninid fish group, i.e., P. herzi, Sarcocheilichthys spp., Squalidus spp., Pseudogobio esocinus, Hemibarbus longirostris, and Hemibarbus labeo, 841 (92.7\%) fishes were infected with 117 CsMc per fish infected. Total 250 (54.7\%) acheilognathinid fish (bitterlings), Acheilognathus spp. and Acanthorhodeus spp. were infected with 5.8 CsMc. In the rasborinid fish (chubs) group, i.e., Zacco platypus, Zacco temminckii, and Zacco koreanus, 77 (13.7\%) out of 563 fish examined were infected with 2.4 CsMc in average. The susceptibility indices of CsMc were 49.09 in the overall positive fish group, 104.15 in the gobioninid group, 3.17 in the acheilognathinid group and 0.35 in the rasborinid fish group respectively. Only 1 CsMc was detected in 3 fish species, Coreoperca herzi, Channa argus, and Lepomis macrochirus, respectively. Conclusively, it was confirmed that CsMc are moderately prevalent in fishes from Yangcheon in Sancheon-gun, Gyeongsangnam-do, Korea.
\end{abstract}

Key words: Clonorchis sinensis, metacercaria, susceptibility index, Gobioninae, Acheilognathinae, Rasborinae, Cyprinidae, fish host, Yangcheon

\section{INTRODUCTION}

Clonorchiasis, Clonorchis sinensis (Digenea: Opisthorchiidae) infection, is most important among endemic parasitic diseases in the Republic of Korea (Korea). Although the prevalence of this endemic disease was $1.86 \%$ in the nationwide survey on the helminthic infection in Korea, about 932,540 Korean peoples are estimated to be infected with this endemic trematode. Nowadays, it is the highest value among the prevalences of parasitic diseases in Korea [1]. The prevalence of clonorchiasis has maintained at relatively high levels in the residents of riverside areas in Korea [2-6]. Recently, a team of Korean CDC (Division of Vectors and Parasitic Diseases, Centers for Disease

\footnotetext{
- Received 14 March 2019, accepted 25 March 2019

*Corresponding author (wmsohn@gnu.ac.kr) (c) 2019, Korean Society for Parasitology and Tropical Medicine This is an Open Access article distributed under the terms of the Creative Commons Attribution Non-Commercial License (http://creativecommons.org/licenses/by-nc/4.0) which permits unrestricted non-commercial use, distribution, and reproduction in any medium, provided the original work is properly cited.
}

Control and Prevention) [4-6] reported the prevalences of clonorchiasis in the adjacent residents of 5 major rivers, i.e., Nakdong-gang (gang means river), Seomjin-gang, Geum-gang, Yeongsan-gang and Han-gang, in Korea. The riverside area of Gyeongho-gang (a branch stream of Nakdong-gang) in Sancheong-gun, Gyeongsangnam-do has been known as a high endemic area of clonorchiasis [6-10].

Many Korean workers epidemiologically surveyed the freshwater fishes, the human infection sources, to estimate the endemicities of clonorchiasis [11-17]. Especially, Kim et al. [11] widely surveyed freshwater fishes from 34 localities to know the infection status with Clonorchis sinensis metacercariae (CsMc) in Korea. Cho et al. [12] investigated the infection status of CsMc in freshwater fish from 3 wide regions, which were tentatively divided by the latitudinal levels of Korean peninsula. Cho et al. [13] also surveyed on the prevalence of zoonotic trematode metacercariae in freshwater fish from Gangwon-do (do=Province), Korea. Sohn et al. [14] investigated the infection status of digenetic trematode metacercariae including $C$. 
sinensis in freshwater fish from the water systems of Hantangang and Imjingang located in relatively northern regions of Korea. Recently, Sohn et al. [15] and Yoon et al. [17] surveyed the prevalence of CsMc in freshwater fishes from the water systems of Seomjin-gang and Tamjin-gang. Sohn et al. [16] also reported the prevalence and intensity of CsMc in freshwater fish from a highly endemic site, Wicheon (a branch stream of Nakdonggang) (cheon means stream), in Gunwi-gun, Gyeongsangbuk-do, Korea.

Gyeongho-gang is one of the branch stream of Nakdonggang, which rise from a mountinous area (Namdeokyu-san) (san means mountain) of Seosang-myeon (myeon=township) in Hamyang-gun (gun=county), flows via Hamyang-gun and Sancheong-gun and into Jinyang-ho (ho means lake) in Jinjusi (si=city), Gyeongsangnam-do. Yangcheon is one of the branch stream of Gyeongho-gang located in the Saengbiryangmyeon, Sancheong-gun [18]. The riverside area of Yangcheon has been reported as a high endemic area of clonorchiasis [7-9]. However, the infection status with CsMc in fish from this area has not been widely and systematically examined yet. Therefore, we intended to investigate the infection status with CsMc in fishes from Yangcheon for 7 years (2011-2017).

\section{MATERIALS AND METHODS}

\section{Fish collection site and freshwater fishes examined}

We collected total 2,201 freshwater fishes in 26 species in Yangcheon (a branch stream of Gyeongho-gang), which is located in Saengbiryang-myeon, Sancheong-gun (Latitude: 35.37015; Longitude: 128.08025), Gyeongsangnam-do, Korea. The numbers and species of fish by the year examined were as follows.

Total 201 freshwater fish in 14 species were examined in 2011. Fish species (No. of fish) examined were Zacco temminckii (27), Coreoperca herzi (10), Odontobutis platycephala (14), and Carassius auratus (1) including 10 ones with CsMc in Table 1. Total 221 freshwater fish in 11 species were examined in 2012. Fish species (No. of fish) examined were Zacco platypus (29), C. herzi (4), and C. auratus (1) including 8 ones with CsMc in Table 1. Total 644 freshwater fish in 20 species were examined in 2013. Fish species (No. of fish) examined were $C$. auratus (20), C. herzi (19), Liobagrus mediadiposalis (3), O. platycephala (3), Acheilognathus yamatsutae (1), and Z. temminckii (1) including 14 ones with CsMc in Table 1.

Total 291 freshwater fish in 14 species were examined in
2014. Fish species (No. of fish) examined were O. platycephala (13) and Siniperca scherzeri (1) including 12 ones with CsMc in Table 1. Total 183 freshwater fish in 15 species were examined in 2015. Fish species (No. of fish) examined were Z. temminckii (40), C. herzi (2), O. platycephala (1), Micropterus salmoides (1), C. auratus (1), and A. macropterus (1) including 9 ones with CsMc in Table 1.

Total 253 freshwater fish in 16 species were examined in 2016. Fish species (No. of fish) examined were C. auratus (22), Z. temminckii (21), Z. koreanus (20), C. herzi (10), O. platycephala (1), and A. macropterus (1) including 10 ones with CsMc in Table 1. Total 408 fish in 22 species were examined in 2017. Fish species (No. of fish) examined were M. salmoides (36), C. auratus (28), Z. koreanus (20), C. herzi (18), and O. platycephala (4) including 17 ones with CsMc in Table 1.

\section{Examination methods}

All collected fishes were transferred to the laboratory of the Department of Parasitology and Tropical Medicine, Gyeongsang National University College of Medicine, Jinju, Korea. After the identification of fish species, they were individually ground with a mortar or grinder. Each ground fish meat was mixed with artificial gastric juice and the mixture was incubated at $36^{\circ} \mathrm{C}$ for about $2 \mathrm{hr}$. The digested material was filtered with $1 \times 1 \mathrm{~mm}$ of mesh and washed with $0.85 \%$ saline untill the supernatant is clear. The sediment was carefully examined under a stereomicroscope. The metacercariae of $C$. sinensis (CsMc) were separately collected by the general feature $[19,20]$, and they were counted to get hold of infection rates (No. of fish with CsMc/No. of fish examined $\times 100$ ) and densities (No. of CsMc/a fish infected) by fish species. The susceptibility indices of CsMc in each fish species were calculated by the formula, prevalence $/ 100 \times$ mean metacercarial density per fish infected.

\section{RESULTS}

\section{Infection status with CsMc in overall fishes}

The metacercariae of $C$. sinensis were detected in 1,171 (53.2\%) out of 2,201 fishes in 26 species examined, and their average density was 85 per fish infected. In CsMc positive fish species, the number of fish examined was 1,827 (83.0\%) in 21 species $(80.8 \%)$, and the positive rate was $64.1 \%$. The infection status by the fish species and surveyed years was detailedly shown in Table 1. 
Table 1. Infection status of Clonorchis sinensis metacercariae in fishes from Yangcheon (a stream of Gyeongho-gang) in Sancheonggun, Gyeongsangnam-do

\begin{tabular}{|c|c|c|c|c|}
\hline \multirow{2}{*}{ Year and fish sp. } & \multirow{2}{*}{ No. of fish examined } & \multirow{2}{*}{ No. of fish infected (\%) } & \multicolumn{2}{|c|}{ No. of CsMc detected } \\
\hline & & & Range & Average \\
\hline \multicolumn{5}{|l|}{2011} \\
\hline Pungtungia herzi & 95 & $95(100)$ & $4-930$ & 157.2 \\
\hline Zacco platypus & 16 & $1(6.3)$ & - & 1.0 \\
\hline Squalidus chankaensis & 13 & $13(100)$ & 14-322 & 95.1 \\
\hline Squalidus japonicus coreanus & 12 & $12(100)$ & $7-69$ & 23.3 \\
\hline Pseudogobio esocinus & 4 & $4(100)$ & $11-167$ & 57.3 \\
\hline Hemibarbus longirostris & 4 & $3(75.0)$ & - & 1.0 \\
\hline Sarcocheilichthys nigripinnis & 2 & $2(100)$ & $43-96$ & 69.5 \\
\hline Hemibarbus labeo & 1 & $1(100)$ & - & 6.0 \\
\hline Sarcocheilichthys variegatus & 1 & $1(100)$ & - & 512.0 \\
\hline Acheilognathus majusculus & 1 & $1(100)$ & - & 2.0 \\
\hline Subtotal & 149 & $133(89.3)$ & $1-930$ & 130.4 \\
\hline \multicolumn{5}{|l|}{2012} \\
\hline Pungtungia herzi & 106 & $106(100)$ & $2-1,157$ & 168.0 \\
\hline Zacco temminckii & 35 & $3(8.6)$ & $1-2$ & 1.3 \\
\hline Hemibarbus longirostris & 21 & $5(23.8)$ & $1-2$ & 1.4 \\
\hline Sarcocheilichthys nigripinnis & 8 & $8(100)$ & $7-795$ & 205.1 \\
\hline Acheilognathus majusculus & 7 & $2(28.6)$ & $7-12$ & 9.5 \\
\hline Squalidus chankaensis & 5 & $5(100)$ & $18-58$ & 42.6 \\
\hline Acanthorhodeus macropterus & 4 & $1(25.0)$ & - & 1.0 \\
\hline Squalidus gracilis majimae & 1 & $1(100)$ & - & 7.0 \\
\hline Subtotal & 187 & $131(70.1)$ & $1-1,157$ & 150.4 \\
\hline \multicolumn{5}{|l|}{2013} \\
\hline Pungtungia herzi & 142 & $141(99.3)$ & $11-742$ & 152.4 \\
\hline Zacco koreanus & 94 & $2(2.1)$ & - & 1.0 \\
\hline Acheilognathus majusculus & 85 & $40(47.1)$ & $1-10$ & 2.5 \\
\hline Zacco platypus & 55 & 19 (34.5) & $1-13$ & 2.3 \\
\hline Squalidus chankaensis & 51 & $51(100)$ & $7-183$ & 61.3 \\
\hline Hemibarbus longirostris & 34 & 19 (55.9) & $1-3$ & 1.6 \\
\hline Acheilognathus koreensis & 31 & $25(80.6)$ & $1-20$ & 5.3 \\
\hline Squalidus japonicus coreanus & 30 & $30(100)$ & $1-134$ & 33.7 \\
\hline Pseudogobio esocinus & 20 & $18(90.0)$ & $2-23$ & 7.8 \\
\hline Acanthorhodeus gracilis & 20 & $3(15.0)$ & - & 1.0 \\
\hline Acanthorhodeus macropterus & 17 & $3(17.6)$ & - & 1.0 \\
\hline Sarcocheilichthys variegatus & 8 & $8(100)$ & $56-530$ & 227.9 \\
\hline Acheilognathus rhombeus & 8 & $5(62.5)$ & $1-5$ & 2.6 \\
\hline Sarcocheilichthys nigripinnis & 2 & $2(100)$ & $21-153$ & 87.0 \\
\hline Subtotal & 597 & $366(61.3)$ & $1-742$ & 76.8 \\
\hline \multicolumn{5}{|l|}{2014} \\
\hline Pungtungia herzi & 65 & $65(100)$ & $1-443$ & 114.3 \\
\hline Acheilognathus majusculus & 40 & $9(22.5)$ & $1-8$ & 2.9 \\
\hline Zacco koreanus & 40 & $1(2.5)$ & - & 1.0 \\
\hline Coreoperca herzi & 30 & $1(3.3)$ & - & 1.0 \\
\hline Zacco platypus & 25 & $13(52.0)$ & $1-10$ & 2.8 \\
\hline Squalidus japonicus coreanus & 25 & $25(100)$ & $9-195$ & 86.7 \\
\hline Pseudogobio esocinus & 16 & $16(100)$ & $1-84$ & 36.8 \\
\hline Acheilognathus koreensis & 13 & $9(69.2)$ & $1-7$ & 3.2 \\
\hline Acheilognathus yamatsutae & 10 & $6(60.0)$ & $1-7$ & 2.7 \\
\hline Hemibarbus longirostris & 7 & $5(71.4)$ & $1-12$ & 5.8 \\
\hline Sarcocheilichthys variegatus & 5 & $5(100)$ & $2-13$ & 8.0 \\
\hline Sarcocheilichthys nigripinnis & 1 & $1(100)$ & - & 29.0 \\
\hline Subtotal & 277 & $156(56.3)$ & $1-443$ & 66.6 \\
\hline
\end{tabular}

(Continued to the next page)

Infection status with CsMc in index fish, Pungtungia herzi

CsMc were detected in 532 (99.6\%) out of 534 P. herzi examined and their average density was 147 per fish infected.
The densities were most high in 2015 (179), and followed by 2012 (168), 2011 (157), 2013 (152), 2016 (145), 2014 (114), and 2017 (89). The infection status with CsMc in P. herzi by 
Table 1. Continued

\begin{tabular}{|c|c|c|c|c|}
\hline \multirow{2}{*}{ Year and fish sp. } & \multirow{2}{*}{ No. of fish examined } & \multirow{2}{*}{ No. of fish infected (\%) } & \multicolumn{2}{|c|}{ No. of CsMc detected } \\
\hline & & & Range & Average \\
\hline \multicolumn{5}{|l|}{2015} \\
\hline Pungtungia herzi & 40 & $40(100)$ & $9-434$ & 178.8 \\
\hline Zacco platypus & 40 & $18(45.0)$ & $1-10$ & 2.6 \\
\hline Hemibarbus longirostris & 25 & $2(8.0)$ & - & 1.0 \\
\hline Sarcocheilichthys variegatus & 10 & $10(100)$ & $42-362$ & 224.3 \\
\hline Acheilognathus majusculus & 9 & 3 (33.3) & $2-6$ & 3.3 \\
\hline Acheilognathus koreensis & 7 & $6(85.7)$ & $1-5$ & 2.0 \\
\hline Acheilognathus yamatsutae & 3 & $3(100)$ & $1-5$ & 2.3 \\
\hline Squalidus japonicus coreanus & 2 & $2(100)$ & $98-194$ & 146.0 \\
\hline Pseudogobio esocinus & 1 & $1(100)$ & - & 12.0 \\
\hline Subtotal & 137 & $85(62.0)$ & $1-434$ & 115.0 \\
\hline \multicolumn{5}{|l|}{2016} \\
\hline Acheilognathus koreensis & 40 & $25(62.5)$ & $1-9$ & 2.9 \\
\hline Pungtungia herzi & 33 & $33(100)$ & $23-341$ & 144.8 \\
\hline Zacco platypus & 32 & $14(43.8)$ & $1-7$ & 2.8 \\
\hline Acheilognathus majusculus & 23 & $13(56.5)$ & $1-16$ & 2.8 \\
\hline Acheilognathus rhombeus & 20 & $19(95.0)$ & $6-51$ & 23.1 \\
\hline Acheilognathus yamatsutae & 13 & $9(69.2)$ & $1-5$ & 1.4 \\
\hline Channa argus & 6 & $1(16.7)$ & - & 1.0 \\
\hline Squalidus japonicus coreanus & 5 & $5(100)$ & $25-162$ & 97.0 \\
\hline Hemibarbus longirostris & 4 & $3(75.0)$ & $1-8$ & 3.7 \\
\hline Pseudogobio esocinus & 2 & $2(100)$ & $28-35$ & 31.5 \\
\hline Subtotal & 277 & $156(56.3)$ & $1-443$ & 66.6 \\
\hline \multicolumn{5}{|l|}{2017} \\
\hline Pungtungia herzi & 53 & $52(98.1)$ & $6-451$ & 89.0 \\
\hline Zacco platypus & 38 & 5 (13.2) & $1-4$ & 2.2 \\
\hline Acheilognathus majusculus & 37 & $18(48.6)$ & $1-10$ & 2.4 \\
\hline Acheilognathus yamatsutae & 31 & $21(67.7)$ & $1-12$ & 3.3 \\
\hline Zacco temminckii & 30 & $1(3.3)$ & - & 1.0 \\
\hline Lepomis macrochirus & 25 & $1(4.0)$ & - & 1.0 \\
\hline Acanthorhodeus gracilis & 21 & $18(85.7)$ & $1-59$ & 17.1 \\
\hline Pseudogobio esocinus & 18 & $18(100)$ & $1-124$ & 34.2 \\
\hline Squalidus japonicus coreanus & 15 & $15(100)$ & $15-364$ & 133.7 \\
\hline Hemibarbus labeo & 8 & $6(75.0)$ & $1-6$ & 2.3 \\
\hline Hemibarbus longirostris & 7 & $5(71.4)$ & $1-8$ & 2.4 \\
\hline Acheilognathus rhombeus & 7 & $6(85.7)$ & $1-34$ & 11.8 \\
\hline Acheilognathus koreensis & 5 & $3(60.0)$ & $1-3$ & 2.3 \\
\hline Squalidus gracilis majimae & 3 & $3(100)$ & $32-195$ & 86.7 \\
\hline Acanthorhodeus macropterus & 2 & $2(100)$ & $4-7$ & 5.5 \\
\hline Sarcocheilichthys nigripinnis & 1 & $1(100)$ & - & 172.0 \\
\hline Sarcocheilichthys variegatus & 1 & $1(100)$ & - & 208.0 \\
\hline Subtotal & 302 & $176(58.3)$ & $1-451$ & 48.0 \\
\hline Total & 1,827 & $1,171(64.1)$ & $1-1,157$ & 85.1 \\
\hline
\end{tabular}

the year examined was detailedly revealed in Table 2.

\section{Infection status with CsMc in gobioninid fish group}

CsMc were detected in 841 (92.7\%) out of 907 fishes in 9 species including $P$. herzi and their average density was 117 per fish infected. The densities were most high in Sarcocheilichthys spp. (179), and followed by P. herzi (147), Squalidus spp. (68), P. esocinus (28), H. labeo (3), and H. longirostris (2). The infection status by the fish species in this group was detailedly shown in Table 3.
Infection status with CsMc in acheilognathinid fish group

CsMc were detected in 250 (54.7\%) out of 457 fishes examined and their average density was 5.8 per fish infected. The infection status with $\mathrm{CsMc}$ by the fish species, i.e., A. majusculus, A. koreensis, A. yamatsutae, A. gracilis, A. rhombeus, and A. macropterus, was detailedly revealed in Table 4.

\section{Infection status with CsMc in rasborinid fish group}

CsMc were detected in 77 (13.7\%) out of 563 fishes examined and their average density was 2.4 per fish infected. The in- 
Table 2. Infection status of Clonorchis sinensis metacercariae in index fish (striped shinner), Pungtungia herzi, from Yangcheon in Sancheong-gun, Gyeongsangnam-do

\begin{tabular}{lrrrr}
\hline & No. of fish examined & No. of fish infected (\%) & \multicolumn{2}{c}{ No. of CsMc detected } \\
\cline { 4 - 5 } & & & Range & Average \\
2011 & 95 & $95(100)$ & $4-930$ & 157.2 \\
2012 & 106 & $106(100)$ & $2-1,157$ & 168.0 \\
2013 & 142 & $141(99.3)$ & $11-742$ & 152.4 \\
2014 & 65 & $65(100)$ & $9-443$ & 114.3 \\
2015 & 40 & $40(100)$ & $23-341$ & 178.8 \\
2016 & 33 & $33(100)$ & $6-451$ & 144.8 \\
Total & 53 & $52(98.1)$ & $1-1,157$ & 89.0 \\
\hline
\end{tabular}

Table 3. Infection status of Clonorchis sinensis metacercariae by the fish species in the gobioninid group (subfamily Gobioninae)

\begin{tabular}{lrrrr}
\hline Species of fish & No. of fish examined & No. of fish infected (\%) & \multicolumn{2}{c}{ No. of CsMc detected } \\
\cline { 4 - 5 } Pungtungia herzi & 534 & $532(99.6)$ & $1-1,157$ & 147.0 \\
Sarcocheilichthys spp. & 39 & $39(100)$ & $2-795$ & 179.0 \\
S. variegatus wakiyae & 25 & $25(100)$ & $2-530$ & 193.0 \\
S. nigripinnis morii & 14 & $14(100)$ & $7-795$ & 153.9 \\
Squalidus spp. & 162 & $162(100)$ & $1-364$ & 68.4 \\
S. japonicus coreanus & 89 & $89(100)$ & $1-364$ & 70.1 \\
S. chankaensis tsuchigae & 69 & $69(100)$ & $7-322$ & 66.3 \\
S. gracilis majimae & 4 & $4(100)$ & $7-195$ & 66.8 \\
Pseudogobio esocinus & 61 & $59(96.7)$ & $1-124$ & 27.9 \\
Hemibarbus longirostris & 102 & $42(41.2)$ & $1-12$ & 2.2 \\
Hemibarbus labeo & 9 & $7(77.8)$ & $1-6$ & 2.9 \\
Total & 907 & $841(92.7)$ & $1-1,157$ & 116.6 \\
\hline
\end{tabular}

Table 4. Infection status of Clonorchis sinensis metacercariae by the fish species in the acheilognathinid group (subfamily Acheilognathinae)

\begin{tabular}{lcccc}
\hline \multirow{2}{*}{$\begin{array}{l}\text { Species of fish } \\
\text { No. of fish examined }\end{array}$} & No. of fish infected (\%) & \multicolumn{2}{c}{ No. of CsMc detected } \\
\cline { 3 - 5 } Acheilognathus majusculus & 202 & $86(42.6)$ & Range & $1-16$ \\
Acheilognathus koreensis & 96 & $68(70.8)$ & $1-20$ & 2.8 \\
Acheilognathus yamatsutae & 58 & $39(67.2)$ & $1-12$ & 3.7 \\
Acanthorhodeus gracilis & 41 & $21(51.2)$ & $1-59$ & 1.7 \\
Acheilognathus rhombeus & 35 & $30(85.7)$ & $1-51$ & 1.8 \\
Acanthorhodeus macropterus & 25 & $6(24.0)$ & $1-7$ & 2.5 \\
Total & 457 & $250(54.7)$ & $1-59$ & 5.8 \\
\hline
\end{tabular}

Table 5. Infection status of Clonorchis sinensis metacercariae by the fish species in the rasborinid group (subfamily Rasborinae)

\begin{tabular}{lcccc}
\hline \multirow{2}{*}{ Species of fish } & No. of fish examined & No. of fish infected (\%) & \multicolumn{2}{c}{ No. of CsMc detected } \\
\cline { 4 - 5 } & & & Range & Average \\
\hline Zacco platypus & 235 & $70(29.8)$ & $1-13$ & 2.5 \\
Zacco koreanus & 174 & $3(1.7)$ & $1-2$ & 1.0 \\
Zacco temminckii & 154 & $4(2.6)$ & $1-13$ & 2.4 \\
Total & 563 & $77(13.7)$ & \\
\hline
\end{tabular}

fection status with CsMc by the fish species, i.e., Z. platypus, $Z$. koreanus, and Z. temminckii, was detailedly shown in Table 5.
Susceptibility index of CsMc by the fish groups

The susceptibility indices of CsMc were 54.6 in the overall 
positive fish group, 108.1 in the gobioninid group, 3.2 in the acheilognathinid, and 0.3 in the rasborinid fish group respectively.

\section{DISCUSSION}

By the present study, it was confirmed that CsMc are moderately prevalent in fishes from Yangcheon, in Sancheong-gun, Gyeongsangnam-do, Korea. The infection status was showed with a certain tendency by the subfamily groups, i.e., Gobioninae, Acheilognathinae and Rasborinae, in the cyprinid fish (Family Cyprinidae) hosts of $C$. sinensis like Sohn et al. [16]. The prevalences were $92.7 \%, 54.7 \%$, and $13.7 \%$, and metacercarial densities were 116.6, 5.8, and 2.4 per fish infected in 3 fish groups respectively. When we compared with those of Sohn et al. [16], prevalences (100\%, 79.7\%, and 35.5\%) and metacercarial densities $(1,310,50$, and 15$)$ were much lower in this study. However, we also knew that the endemicity of CsMc is closely related with the subfamily groups in the cyprinid fish hosts of $C$. sinensis from a moderately endemic area, Yangcheon, in Sancheong-gun, Gyeongsangnam-do, Korea.

The water ecosystem of Yancheon is more or less healthy but the ecological conditions for fish is not so good. Total 2,201 freshwater fishes in 26 species were collected through 7 years (2011-2017) in the same site of Saengbiryang-myeon in Sancheong-gun, Gyeongsangnam-do, in this study. Among them, striped shinner (534 P. herzi: 24.3\%), was the most dominant fish species like Yoon et al. [17] in Tamjingang, and followed by pale chub (235 Z. platypus: 10.7\%), large stripted bitterling (202 A. majusculus: 9.2\%), Korean chub (174 Z. koreanus: 7.9\%), dark chub (154 Z. temminckii: 7.0\%), long nose barbel (102 H. longirostris: 4.6\%), and oily bitterling (96 A. koreensis: $4.4 \%)$. The number of fish examined was 1,497 (68.0\%) in major 7 species and 704 (32.0\%) in remain 19 species. The disproportion of fish number examined is suggested that the ecological conditions for fish was relatively not so good, and because of all fishes were collected only by the netting in the nighttime. If we used together with other methods for fish catching like a casting net, the more various species of fish including diurnal ones were able to collect.

Total 51 fish species (in 36 genera 9 families) have been reported as the second intermediate hosts of $C$. sinensis in Korea $[11,12,15-17,19]$. In the present study, CsMc were found in 21 fish species, i.e., P. herzi, S. variegatus wakizae, S. nigripinnis morii, S. japonicus coreanus, S. chankaensis tsuchigae, S. gracilis maji- mae, P. esocinus, H. longirostris, H. labeo, A. majusculus, A. koreensis, A. yamatsutae, A. gracilis, A. rhombeus, A. macropterus, Z. platypus, Z. koreanus, Z. temminckii, C. herzi, Channa argus, and Lepomis macrochirus. Among them, 2 fish species, i.e., L. macrochirus (Centrachidae) and C. argus (Channidae), are to be newly added in the list of the second intermediate hosts of $C$. sinensis in Korea. Accordingly, total 53 fish species in 38 genera (10 families) are to be the second intermediate hosts of C. sinensis in Korea.

The blue gill, L. macrochirus, was imported from Japan in 1969 and stocked in the Korean ecosystems in 1975 as the edible fish species. However, this predatory fish was widely spread in the water systems of whole country, and then specified as an agitating fish species of ecosystem in Korea [21]. In this study, no CsMc were detected in 5 (19.2\%) out of 26 fish species examined, i.e., Carassius auratus $(\mathrm{n}=73)$, Micropterus salmoides (37), Odontobutis platycephala (36), Liobagrus mediadiposalis (3), Siniperca scherzeri (1), and only 1 CsMc was found in $1(4.0 \%)$ out of 25 blue gills examined. Infections with CsMc in 2 exotic fish species, L. macrochirus and M. salmoides [16], are meaningful, although the number of fish examined and metacercariae detected were not so many. On the other hand, Choe et al. [22] did not found any other zoonotic trematode metacercariae including $C$. sinensis in 107 large mouth bass (M. salmoides) and 244 blue gills (L. macrochirus) from 2 sites, Daecheong-ho and Musimcheon, of Chungcheongbukdo, Korea. However, we should pay attention to the exotic fish species, such as large mouth bass and blue gill, in the metacercarial survey for the fishborne zoonotic trematodes.

Fish species edible in the raw, i.e., Mandarin fish (S. scherzeri), Korean aucha perch (C. herzi), dark sleeper (Odontobutis spp.), common carp (Cyprinus carpio), and crusian carp (C. auratus), practically act as the infection source of clonorchiasis in Korea. Fortunately, these fish species are less prevalent with CsMc. In even such a highly endemic area, Wicheon, $3(8.8 \%)$ out of 34 C. auratus were infected with total 3 CsMc, 2 (11.1\%) C. herzi were retained with a total of 4 CsMc and only $1(33.3 \%) S$. scherzeri were infected with total 6 CsMc [16]. No CsMc were detected in 4 fish species, i.e., $C$. herzi $(\mathrm{n}=57)$, C. auratus (42), $S$. scherzeri (11), and C. carpio (2), from the water systems of Seomjingang [18]. In this study, only one CsMc were found in only 1 (1.1\%) out of $93 \mathrm{C}$. herzi and no CsMc were detected from $73 \mathrm{C}$. auratus, 36 O. platycephala, and 1 S. scherzeri.

So, the striped shinner, $P$. herzi, broadly live in the water systems of river in Korea and is highly susceptibe with CsMc, it is 
appropriate to evaluate the endemicities of $C$. sinensis infection as the index fish species. The number of this fish species examined were 197 (12.3\%) in Seomjin-gang [15], 222 (13.5\%) in Tamjin-gang [17], 169 (14.5\%) in Wicheon [16], and 534 (24.3\%) in this study. In the present study, 532 (99.6\%) P. herzi were infected with $147 \mathrm{CsMc}$ in average. Therefore, the endemicity (susceptibility index) was 146.4 (87.3-178.8 by the year examined). This value is higher than those in Tamjingang (103.2) [17] and Seomjin-gang (34.8) [15]. However, it is very low when we compared with that $(1,550)$ in Wicheon [16]. Accordingly, based on the endemicity of CsMc in the index fish, $P$. herzi, we can know that Wicheon is highly endemic, Yangcheon in this study and Tamjin-gang are moderately endemic and Seomjin-gang is more or less low endemic areas.

In a highly endemic area, Wicheon in Gunwi-gun, Gyeongsangbuk-do, the infection tendency with CsMc was observed in positive fish species by the subfamily groups, i.e., Gobioninae, Acheilognathinae and Rasborinae, in the Cyprinidae fish hosts [16]. The endemicites in each group were 1,310.0, 39.9, and 5.3. Meanwhile, in this study performed in the moderately endemic area, they were $130.9,3.2$, and 0.3 . The difference of endemicity between 2 regions was about 10 times in gobioninid group, 12.5 times in acheilognathinid and 17.7 times in rasborinid fish group. These findings suggest that the endemicity of CsMc is closely related with the fish groups in the cyprinid fish hosts and the endemicity difference in each fish groups from 2 regions is smaller in the susceptible gobioninid fish group, which is strongly related with host-parasite relationship, such as the infectivity of cercariae and susceptibility of host fish.

Conclusively, it is confirmed that the endemicity of CsMc is the moderate level in fishes from Yangcheon and the infection tendency of CsMc is obviously showed by the subfamily groups, i.e., Gobioninae, Acheilognathinae and Rasborinae, in the family Cyprinidae fish hosts from a moderately endemic site.

\section{ACKNOWLEDGMENTS}

This study was supported by an anti-communicable diseases control program, 2014-E54002-00 (Investigation of fish-borne parasites and acquisition of their biological resources in the southern regions of Korea) of National Institute of Health (NIH), Korea Centers for Disease Control and Prevention (KCDCP), and a grant from Korea Association of Health Promotion (KAHP-2017: Survey on the effects of migratory bird in the infection status of trematode metacercariae in fish from Junam Reservoir). We thank Jung-A Kim and Hee-Joo Kim (Department of Parasitology and Tropical Medicine, Gyeongsang National University College of Medicine, Jinju, Korea), for their help in the examination of fish.

\section{CONFLICT OF INTEREST}

The authors have no conflicts of interest concerning the work reported in this paper.

\section{REFERENCES}

1. Korea National Institute of Health, Korea Centers for Disease Control and Prevention. National survey of the prevalence of intestinal parasitic infections in Korea, 2012-The 8th Report. Osong Chungcheongbuk-do, Korea, 2013.

2. Seo BS, Lee SH, Cho SY, Chai JY, Hong ST, Han IS, Sohn JS, Cho BH, Ahn SR, Lee SK, Chung SC, Kang KS, Shim HS, Hwang IS. An epidemiologic study on clonorchiasis and metagonimiasis in riverside areas in Korea. Korean J Parasitol 1981; 19: 137-150.

3. Rim HJ. The current pathobiology and chemotherapy of clonorchiasis. Korean J Parasitol 1986; 24 (suppl): 1-141.

4. Cho SH, Lee KY, Lee BC, Cho PY, Cheun HI, Hong ST, Sohn WM, Kim TS. Prevalence of clonorchiasis in southern endemic areas of Korea in 2006. Korean J Parasitol 2008; 46: 133-137.

5. Kim HK, Cheun HI, Chung BS, Lee KY, Kim TS, Lee SE, Lee WJ, Cho SH. Prevalence of Clonorchis sinensis infections along the five major rivers in Republic of Korea, 2007. Osong Public Health Res Perspect 2010; 1: 43-49.

6. Jeong YI, Shin HE, Lee SE, Cheun HI, Ju JW, Kim JY, Park MY, Cho SH. Prevalence of Clonorchis sinensis infection among residents along 5 major rivers in the Republic of Korea. Korean J Parasitol 2016; 54: 215-219.

7. Bae KH, Ahn YK, Soh CT, Tsutsumi H. Epidemiological studies on Clonorchis sinensis infection along the Nam-river in Gyeongnam Province, Korea. Korean J Parasitol 1983; 21: 167-186 (In Korean).

8. Lee JS, Lee WJ, Kim TS, In TS, Kim WS, Kim SK. Current status and the changing pattern of the prevalence of clonorchiasis in the inhabitants in Sanchon-gun, Kyongsangnam-do, Korea. Korean J Parasitol 1993; 31: 207-213 (In Korean).

9. Hong SJ, Lee YH, Chung MH, Lee DH, Woo HC. Egg positive rates of Clonorchis sinensis and intestinal helminths among residents in Kagye-ri, Saengbiryang-myon, Sanchong-gun, Kyongsangnam-do. Korean J Parasitol 1994; 32: 271-273.

10. Kim BJ, Ock MS, Kim IS, Yeo UB. Infection status of Clonorchis sinensis in residents of Hamyang-gun, Gyeongsangnam-do, Korea. Korean J Parasitol 2002; 40: 191-193.

11. Kim EM, Kim JL, Choi SY, Kim JW, Kim S, Choi MH, Bae YM, Lee SH, Hong ST. Infection status of freshwater fish with meta- 
cercariae of Clonorchis sinensis in Korea. Korean J Paraitol 2008; 46: 247-251.

12. Cho SH, Sohn WM, Na BK, Kim TS, Kong Y, Eom K, Seok WS, Lee T. Prevalence of Clonorchis sinensis metacercariae in freshwater fish from three latitudinal regions of the Korean Peninsula. Korean J Parasitol 2011; 49: 385-398.

13. Cho SH, Lee WJ, Kim TS, Seok WS, Lee TJ, Jeong KJ, Na BK, Sohn WM. Prevalence of zoonotic trematode metacercariae in freshwater fish from Gangwon-do, Korea. Korean J Parasitol 2014; 52: 399-412.

14. Sohn WM, Na BK, Cho SH, Lee SW, Choi SB, Seok WS. Trematode metacercariae in freshwater fish from water systems of Hantangang and Imjingang in Republic of Korea. Korean J Parasitol 2015; 53: 289-298.

15. Sohn WM, Na BK, Cho SH, Park MY, Kim CH, Hwang MA, No KW, Yoon KB, Lim HC. Prevalence of Clonorchis sinensis metacercariae in fish from water systems of Seomjin-gang (River). Korean J Parasitol 2017; 55: 305-312.

16. Sohn WM, Na BK, Cho SH, Ju JW, Son DC. Prevalence and intensity of Clonorchis sinensis metacercariae in freshwater fish from
Wicheon Stream in Gunwi-gun, Gyeongsangbuk-do, Korea. Korean J Parasitol 2018; 56: 43-50.

17. Yoon KB, Lim HC, Jeon DY, Park S, Cho SH, Ju JW, Shin SS, Na $\mathrm{BK}$, Sohn WM. Infection status with Clonorchis sinensis metacercariae in fish from Tamjin-gang (River) in Jeollanam-do, Republic of Korea. Korean J Parasitol 2018; 56: 183-188.

18. Gyeongho-gang in Gyeongnam Province (South Korea) in Wikipedia - The free ency-clopedia; http://en.wikipedia.org.

19. Sohn WM. Fish-borne zoonotic trematode metacercariae in the Republic of Korea. Korean J Parasitol 2009; 47 (suppl): 103-113.

20. Sohn WM. Invertebrate Founa of Korea Vol. 6, No. 1. Trematodes. Incheon, Korea. The National Institute of Biological Resources. 2013, pp 1-125.

21. Kim IS, Kang EJ. Coloured Fishes of Korea. Seoul, Korea. Academy Publishing Company. 1993, pp 1-477 (in Korean).

22. Choe S, Park H, Lee D, Kang Y, Jeon HK, Eom KS. Infections with digenean trematode metacercariae in two invasive alien fish, Micropterus salmoides and Lepomis macrochirus, in two rivers in Chungcheongbuk-do, Republic of Korea. Korean J Parasitol 2018; 56: 509-513. 